\title{
Multi-Scale Modeling of Solid Oxide Fuel Cells: From Patterned Anodes to a Power Plant System
}

\author{
Wolfgang G. Bessler ${ }^{\mathrm{a}, \mathrm{b}}$ \\ ${ }^{a}$ German Aerospace Center (DLR), Institute of Technical Thermodynamics \\ Pfaffenwaldring 38-40, 70569 Stuttgart, Germany \\ ${ }^{\mathrm{b}}$ Institute of Thermodynamics and Thermal Engineering, Universität Stuttgart, Germany
}

\begin{abstract}
Methods of mathematical modeling and numerical simulation of solid oxide fuel cells (SOFCs) are increasingly being used as tool to understand and optimize both, fundamental electrochemical properties and technological applications. The goal of modeling activities is to identify critical components and processes responsible for cell and system performance, lifetime and cost. We present a multi-scale and multi-physics modeling and simulation methodology that covers (i) elementary kinetics on the surfaces, (ii) properties of porous electrodes, (iii) mass, charge and heat transport of cells and stack repeat elements, and (iv) system integration with balance-of-plant components. The coupling over the various scales is realized via tailored simulation programs and software interfaces. Various examples are given. The activities demonstrate the viability of a multi-scale and multi-physics modeling approach for both, understanding fundamental processes and supporting application design of SOFCs.
\end{abstract}

\section{Introduction}

Methods of mathematical modeling and numerical simulation of solid oxide fuel cells (SOFCs) are increasingly being used as tool to understand and optimize both, fundamental electrochemical properties and technological applications. The goal of modeling activities is to identify critical components and processes responsible for cell and system performance, lifetime and cost. To this goal, a large number of different physical, chemical and fluid mechanical processes ("multi-physics") that take place over a wide range of spatial and temporal scales ("multi-scale") have to be considered. This represents a considerable challenge for theoreticians not only during the course of model development, but also when performing numerical simulations with different software codes that are typically specialized towards particular processes and scales.

We present a multi-scale and multi-physics modeling and simulation methodology that covers $(i)$ elementary kinetics on the surfaces, (ii) properties of porous electrodes, (iii) mass, charge and heat transport of cells and stack repeat elements, and (iv) system integration with balance-of-plant components. The cell and sub-cell scales are modeled using the in-house simulation software DENIS (detailed electrochemistry and numerical impedance simulation) (1). Elementary kinetic and thermodynamic properties are calculated via the software CANTERA (2). These codes are directly coupled to the system simulation software SIMULINK and the CFD software ANSYS. 


\section{Multi-Scale Modeling and Simulation Methodology}

\section{$\underline{\text { Overview }}$}

The fuel cell is an outstanding example for a multi-scale system. This situation is shown schematically in Figure 1. Electrochemical reactivity takes place on a nanometer scale and strongly depends on nano- and microstructural properties. Mass, charge and

\begin{tabular}{|c|c|c|c|c|}
\hline Level & Scale & Chemistry & Transport & $\begin{array}{l}\text { Simulation } \\
\text { method }\end{array}$ \\
\hline System & $\begin{array}{l}10^{0} \mathrm{~m} \\
10^{4} \mathrm{~s}\end{array}$ & & $\begin{array}{l}\text { Mass, } \\
\text { energy, } \\
\text { exergy fluxes }\end{array}$ & $\begin{array}{l}\text { Process } \\
\text { simulation } \\
\text { with } \\
\text { MATLAB- } \\
\text { SIMULINK }\end{array}$ \\
\hline Stack & $\begin{array}{c}10^{-1} \mathrm{~m} \\
10^{2} \mathrm{~s}\end{array}$ & & $\begin{array}{l}\text { Laminar flow, } \\
\text { heat } \\
\text { conduction, } \\
\text { radiation }\end{array}$ & $\begin{array}{l}\text { Compu- } \\
\text { tational fluid } \\
\text { dynamics } \\
\text { (CFD) with } \\
\text { ANSYS }\end{array}$ \\
\hline Cell & $\begin{array}{c}10^{-2} \mathrm{~m} \\
10^{0} \mathrm{~s}\end{array}$ & $\begin{array}{l}\text { Gas-phase } \\
\text { chemistry }\end{array}$ & $\begin{array}{l}\text { Laminar flow, } \\
\text { heat } \\
\text { convection }\end{array}$ & $\begin{array}{l}\text { Heat, mass } \\
\text { and charge } \\
\text { transport } \\
\text { with DENIS }\end{array}$ \\
\hline $\begin{array}{l}\text { Elec- } \\
\text { trode }\end{array}$ & $\begin{array}{l}10^{-4} \mathrm{~m} \\
10^{-2} \mathrm{~s}\end{array}$ & $\begin{array}{l}\text { Thermal \& } \\
\text { Redox } \\
\text { cycling } \\
\text { Defect } \\
\text { chemistry }\end{array}$ & $\begin{array}{l}\text { Porous multi- } \\
\text { phase mass } \\
\text { and charge } \\
\text { transport }\end{array}$ & $\begin{array}{l}\text { Continuum } \\
\text { transport and } \\
\text { percolation } \\
\text { theory with } \\
\text { DENIS }\end{array}$ \\
\hline Surface & $\begin{array}{l}10^{-8} \mathrm{~m} \\
10^{-6} \mathrm{~s}\end{array}$ & $\begin{array}{l}\text { Surface } \\
\text { chemistry }\end{array}$ & $\begin{array}{l}\text { Surface } \\
\text { diffusion }\end{array}$ & $\begin{array}{l}\text { Mean field } \\
\text { elementary } \\
\text { kinetics with } \\
\text { CANTERA }\end{array}$ \\
\hline
\end{tabular}

Figure 1. Multi-scale chemical and transport processes in fuel cells, modeling approach, and simulation methodology. The various software packages are coupled directly within runtime. 
heat transport takes place from a nanometer (atomistic level) up to meter scale (system level). Time scales vary from sub-nanoseconds (electrochemical reactions) over seconds (transport) up to days or even months (structural and chemical degradation). All process are strongly, and often nonlinearly, coupled over the various scales. Processes on the microscale can therefore dominantly influence macroscopic behavior. A detailed understanding of the relevant processes on all scales is required for a computer-based optimization of fuel cell design, performance and durability.

There are a number of different methods available for modeling the processes on the various scales. These methods are generally highly specialized and highly specific, and are usually applied to particular problems within their respective scale. This is of high importance and has lead to a considerable insight into fuel cell processes at all scales. However, the coupling between the scales is often not considered. Indeed, bridging the gap between the scales is a particular challenge. This is so not only because of the complex interaction of physicochemical processes on different scales, but also (and maybe dominantly) because of the specialization of different research groups on individual scales and their methods.

Multi-scale methods can be generally separated into two main principles, $(i)$ indirect coupling, also referred to as vertical coupling, by using results from one scale as input parameters to the other scale, and (ii) direct coupling, also referred to as horizontal coupling, by including lower-scale physics into higher-scale models within simulation runtime. An example for case $(i)$ is the use of quantum-chemistry based parameters in elementary kinetic cell-level models. An example for case (ii) is the integration of a celllevel model into system simulation software.

Our simulations are carried out using the in-house software package DENIS (detailed electrochemistry and numerical impedance simulation) (1). Chemistry is coupled to continuum transport models taking place on three different scales, $(i)$ surface diffusion on the nano-/micrometer scale, (ii) gas-phase and charge transport in porous composite electrodes on the micrometer scale, (iii) mass and heat transport in the flow channels on the centimeter scale. Each single scale is modeled in one dimension; the coupling of all scales therefore yields a quasi-3D or $(1 \mathrm{D}+1 \mathrm{D}+1 \mathrm{D})$ model. Depending on the application, only a part of the scales are used. Spatial discretization is carried out using a finitevolume scheme. For transient numerical solution the implicit DAE solver LIMEX is used $(3,4)$. For further extending the scales, DENIS has interfaces for coupling with external codes (CANTERA, ANSYS, SIMULINK) as discussed below.

\section{From the Molecule to the Cell: Elementary Kinetics}

Elementary kinetics means the resolution of chemistry into single steps that represent reactivity on the molecular scale. This approach allows the simulation of atomic-scale processes (e.g., a charge-transfer reaction) in an ensemble-averaged way. The surface is described using averaged quantities like surface coverages and thermodynamic and adsorbate properties. Chemical reactions are modeled using mass-action kinetics. The atomic-scale surface structure (terraces, steps, edges), composition (e.g., impurities) and adsorbate behavior (e.g., end-on or side-on geometry) are not necessarily resolved and are assumed to be included in the averaged quantities. This assumption is also referred to 
as mean-field assumption. Elementary kinetic models of SOFC electrode reactions have recently been reviewed by Adler and Bessler (5).

The high level of detail accessible with elementary kinetic models comes at the cost of a large number of model parameters. In particular, this includes (a) thermodynamic parameters (molar enthalpies and entropies) of all intermediates, (b) kinetic coefficients (preexponential factors, activation energies, symmetry factors) of all elementary reaction steps, and (c) transport properties (surface and bulk diffusion coefficients). The assessment and validation of these parameters is a central task in elementary kinetic modeling. In order to cope with the large number of parameters, we apply a hierarchical approach. For Ni/YSZ anodes, such a hierarchical approach is shown in Figure 2. This figure demonstrates an important feature of elementary kinetic modeling: The reactions are material-specific, but not method- and application-specific. Therefore, parameters that are obtained using various experimental or theoretical methods can be used in a different chemical context involving the same material. Furthermore, any sub-set of elementary reactions can be independently validated, and then used as part of a larger elementarystep mechanism. Thus, each elementary step is directly or indirectly accessible through multiple experimental and theoretical methods. This is includes surface spectroscopy techniques for validating thermodynamics properties (LEED, AES, XPS, STM, etc.) as well as kinetic techniques for determining kinetic properties (TPD/O/R etc.). Parameters for charge-transfer reactions are accessible through standard electrochemical measurements (EIS, CV, RDE etc.), preferably through the use of particularly-designed model electrodes (patterned or point electrodes). Thermodynamic and kinetic coefficients can also be obtained from atomistic models such as density-functional theory (DFT) in a vertical coupling scheme.

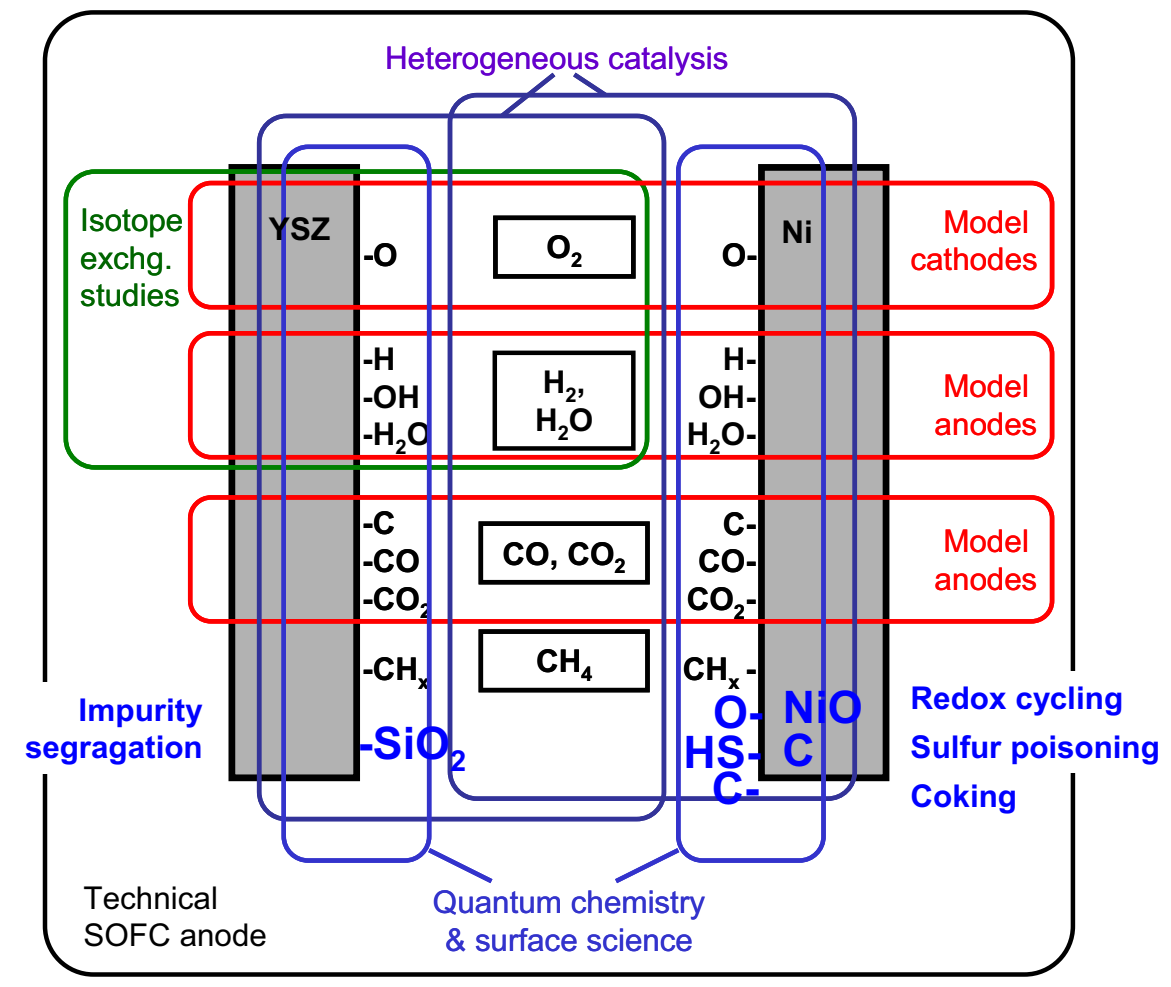

Figure 2. Combination of different chemical processes (regular and degradation reactions) to a complete elementary kinetic model of an SOFC anode. 
An elementary electrochemical mechanism can easily consist of dozens of species and reactions. In order to evaluate the chemical source terms for species, we use the software CANTERA developed by Goodwin and co-workers (2). CANTERA is an opensource software that allows the simulation of complex reaction systems based on conveniently-structured input files. We have successfully coupled CANTERA modules (written in $\mathrm{C}++$ ) directly to our in-house software code DENIS (written in $\mathrm{C}$ ), making the full CANTERA functionality available during DENIS runtime.

\section{From the Cell to the System: Representative Repeat Elements}

The system level represents the complete fuel cell system, that is, the stack itself and its periphery components such as pumps, blowers, heat exchangers, fuel processing units (e. g., desulphurization, reforming), exhaust gas treatment, ac/dc converter, electronic control, etc. System modeling considers not only mass and energy balances between these components, but also assesses exergy fluxes (i. e., the part of the energy that is available for work) in order to understand and optimize the system's overall efficiency. Yet, there is today a considerable gap in scales (both temporal/spatial scale and complexity scale) between fundamental models on one side and component models on the other side. Lower-scale models are usually "physics-oriented" and include detailed descriptions of electrochemical kinetics, transport processes (both gas-phase and solid phase) and structure. Higher-scale models are "application-oriented" and use simplified (semi-)empirical descriptions for fuel cell and balance-of-plant components. In the fuel cell literature, there is so far only limited coupling between lower-scale and higher-scale models.

The fuel cell stack itself is a geometrically and chemically highly complex system component. In order to allow simulations of the stack behavior on the system level within reasonable computational time (i.e., considerably faster than real time), the concept of using representative repeat elements is applied. This concept takes advantage of the periodic building principle of fuel cell stacks. It is assumed that the global stack behavior can be described by a selection of representative single cells (modeled in 2D or 3D) or even a single channel pair (i.e., air and fuel channel coupled by a MEA, modeled in 1D or 2D). Although strongly simplified from the stack point of view, these models are still based on a physicochemical description of electrochemistry and transport, as compared to empirical performance maps.

For system-level simulations we use the MATLAB/SIMULINK software package. SIMULINK allows a graphically-based modeling of components (that occur as model "blocks") and their interactions. For multi-scale simulations, we couple SIMULINK with DENIS (6). The coupling is established via a SIMULINK system function ("S-function"). This software interface makes the full DENIS functionality available as SIMULINK block. In particular, detailed cell-level models based on a single channel pair are made available on the system level. Input to the block are, for example, gas inflow composition and rate at anode and cathode, temperature, pressure, cell voltage, and system time. The block returns gas outflow composition and rate, cell current and power, as well as spatially resolved cell properties such as local gas concentrations.

It is interesting to note that the numerical solver on the cell level (DENIS) runs independently of the system-level (SIMULINK) solver. This opens a computationally 
elegant way of decoupling time scales: While the system-level model is always solved dynamically, the cell-level model can be solved either dynamically or in steady-state mode. In the latter case, for each time step of the system-level model, the cell-level model provides a stationary solution for the respective input conditions. This allows a significant increase in computational speed. The requirement for using time-scale decoupling is that processes on the cell level (electrochemical reactions, cell-scale transport) are fast compared to processes on the system level (feedback of control loops, inertia of balance-of-plant components) and can be assumed in continuous equilibrium. For many system applications, this assumption holds true.

\section{$\underline{\text { Homogenization and Dimension Reduction }}$}

Many multi-scale methods apply structural homogenization approaches, that is, lower-scale structural information is embedded into the higher-scale model in an averaged (homogenized) way. This is the case, for example, for elementary kinetic electrochemistry models (where the influence of surface nanostructure like steps or kinks is implicitly included in the homogenized rate coefficients such as activation energies) and for continuum porous transport models (where the influence of pore structure is included in the homogenized effective transport coefficients such as effective diffusivities). Although spatial homogenization is often used implicitly or based on common sense, there are also mathematically rigorous treatments of the validity of homogenization approaches (7).

In order to reduce computational effort, models with reduced dimensions are commonly used. With reduced-dimensional models we refer to three different approaches. Firstly, it is common to represent only partial dimensions of the full problem according to the subject of interest (e.g., 2D behavior along a fuel cell channel versus 2D behavior below channel and land). Secondly, and more relevant for multi-scale approaches, spatial dimensions are often decoupled due their difference in scale. For example, planar fuel cells typically have large aspect ratios (cell length in the $10 \mathrm{~cm}$ range versus MEA thickness in the sub-millimeter range). This allows to reduce a full $2 \mathrm{D}$ model (along length and through thickness) to a 1D+1D model, where the MEA is described as a set of 1D models along the length of a 1D channel model. Thirdly, it is common to neglect dimensions due to a difference in transport properties or due to symmetry considerations. For example, the 3D laminar flow in a fuel cell channel is often modeled in 1D only because radial transport is much faster than axial transport, leading to a homogeneous concentration and temperature distribution in the channel cross-sectional area.

\section{Results and Discussion}

\section{$\underline{\text { Patterned Anodes }}$}

The smallest scale covered in the present study is the scale of elementary electrochemistry. We have studied in detail the elementary reaction mechanisms of the SOFC Ni/YSZ anode (8-13) both for $\mathrm{H}_{2}$ and $\mathrm{CO}$ oxidation at the three-phase boundary (TPB) (see Figure 3). The mechanisms were validated using electrochemical experiments with micropatterned anodes by Ivers-Tiffée and co-workers $(10,13)$. The geometry of the patterned anodes was represented as one-dimensional reaction-diffusion model (Figure 4). 


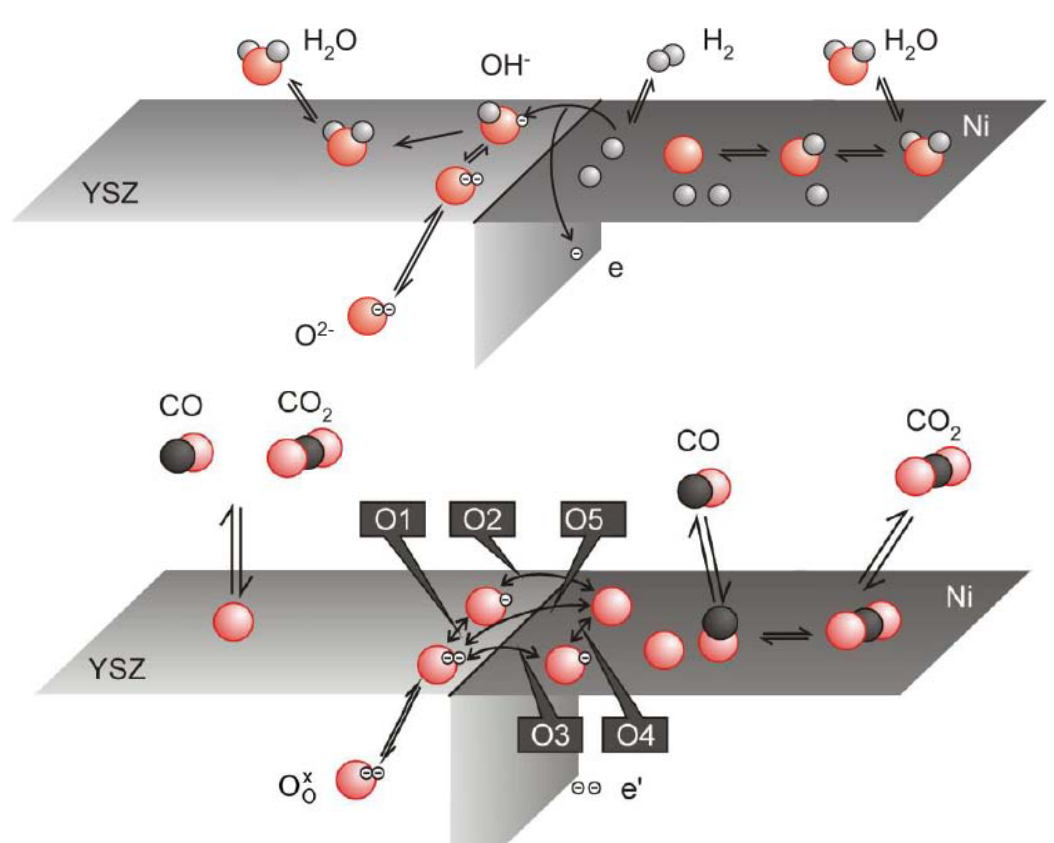

Figure 3. Elementary kinetic mechanisms at a Ni/YSZ/gas three-phase boundary (TPB) used in the present work. Upper figure: $\mathrm{H}_{2}$ oxidation via hydrogen spillover pathway. Lower figure: $\mathrm{CO}$ oxidation via combined oxygen spillover and reactive electrolyte pathways.

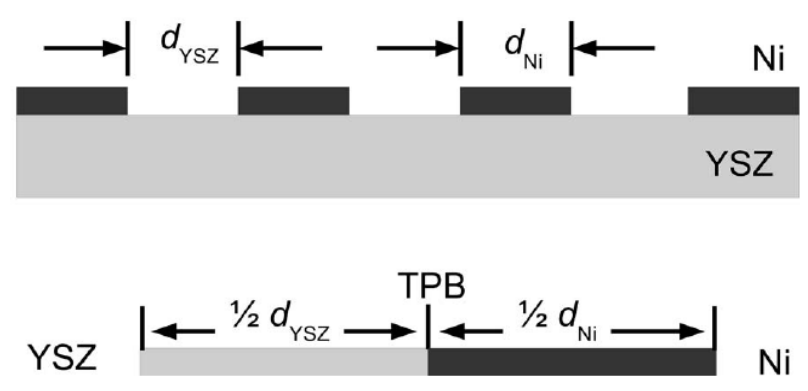

Figure 4. Representation of the patterned electrode (upper figure) as one-dimensional modeling domain (lower figure) for representing surface reactions, diffusion, and spillover charge transfer (13).

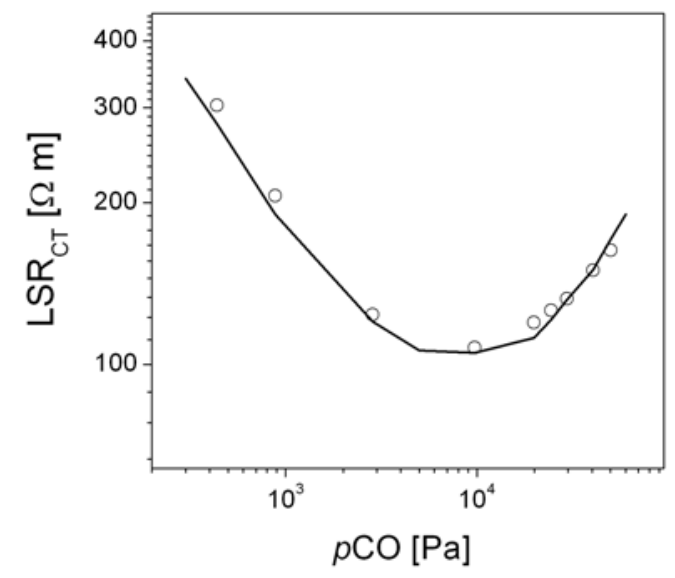

Figure 5. Experimental (open symbols) and simulated (solid line) line-specific chargetransfer resistance $\left(\mathrm{LSR}_{\mathrm{CT}}\right)$ of a $\mathrm{Ni} / \mathrm{YSZ}$ pattern anode as a function of the $\mathrm{CO}$ partial pressure for a fixed $\mathrm{CO}_{2}$ partial pressure of $p \mathrm{CO}_{2}=2 \cdot 10^{4} \mathrm{~Pa}(T=1073 \mathrm{~K})(12)$. 
Figure 5 shows an exemplary result for $\mathrm{CO}$ electrooxidation, where the experimental line-specific resistance (symbols) shows a minimum as a function of $\mathrm{CO}$ partial pressure. The elementary kinetic model (line) based on a mechanism shown in Figure 3 is able to quantitatively reproduce the observation.

\section{$\underline{\text { Cermet Anodes }}$}

On the next higher scale, we use the elementary mechanism in continuum models of porous $\mathrm{Ni} / Y S Z$ cermet electrodes $(14,15)$. Here, the detailed chemistry is coupled to porous gas-phase and solid-phase transport in the composite electrode. The upscaling from patterned anodes to cermet anodes is based on using effective geometrical parameters such as the specific three-phase boundary length (in $\mathrm{m}$ TPB length per $\mathrm{m}^{3}$ electrode volume) and specific surface areas (in $\mathrm{m}^{2}$ surface area per $\mathrm{m}^{3}$ electrode volume).

\section{$\underline{\text { Single Cells }}$}

The next higher scale is the one of a single cell consisting of porous electrodes, solid electrolyte, current collector meshes and flow channels. Here we typically apply 2D models, where one dimension is through the thickness of the membrane-electrode assembly and one dimension is along the length of the channel. The modeling domain is shown in Figure 6. We use decoupled dimensions for gas-phase transport (1D in the porous electrodes and 1D along the channel), but coupled dimensions for ionic transport (2D ion transport and potential distribution in the electrolyte phases of solid electrolyte and composite electrodes).

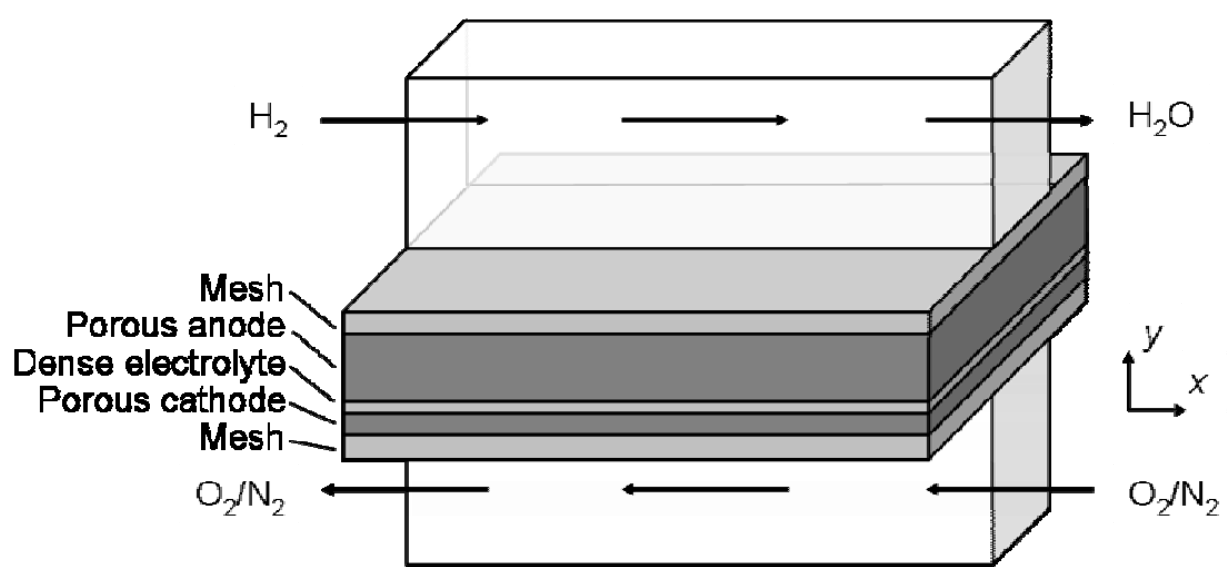

Figure 6. Two-dimensional modeling domain for a single SOFC.

We use this model in different applications. Reforming and water-gas shift rates and gas-phase concentrations were quantified as function of spatial position along flow channel and inside porous electrodes for methane-operated SOFCs $(1,18)$. Segmented SOFCs (Figure 7) were studied in a combined experimental and modeling effort in order to further understand spatial effects $(16,19)$. The influence of pressurization on chemistry and transport was investigated in the context of hybrid power plants $(20,21)$. Recently, we have started to implement chemical degradation mechanisms such as nickel oxidation (17). Simulation results for the spatial distribution of $\mathrm{NiO}$ volume fraction inside a porous anode are shown in Figure 8. 


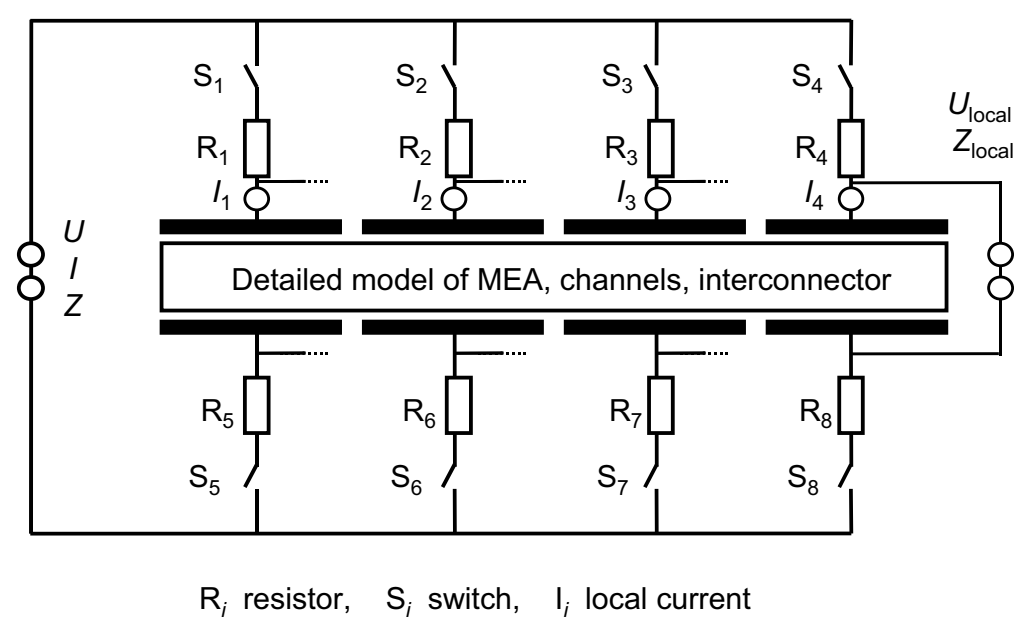

Figure 7. Model of a segmented SOFC, where the segmentation is represented by an electric circuit (16).

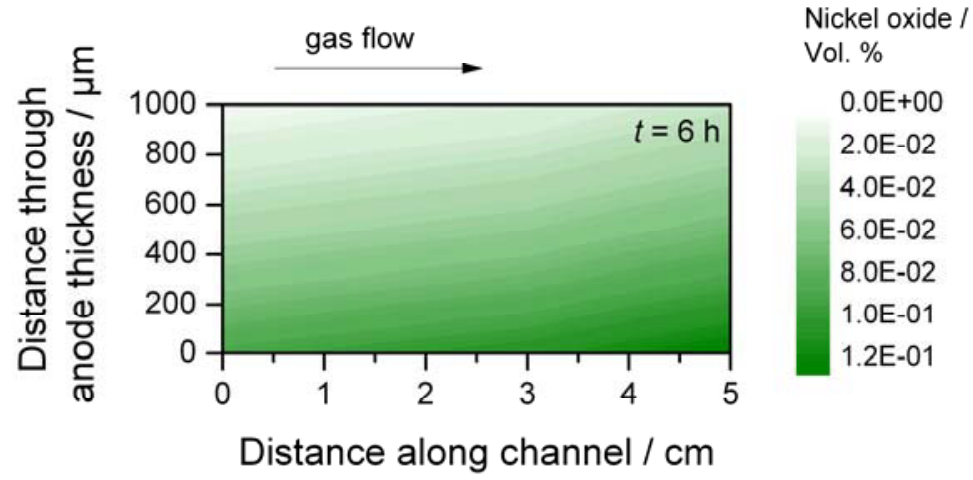

Figure 8. Evolution of nickel oxide formation inside the anode, cell operation at $0.69 \mathrm{~V}$, $\mathrm{H}_{2}: \mathrm{H}_{2} \mathrm{O}=0.97: 0.03$ (17).

\section{$\underline{\text { Solid Oxide Fuel Cell System }}$}

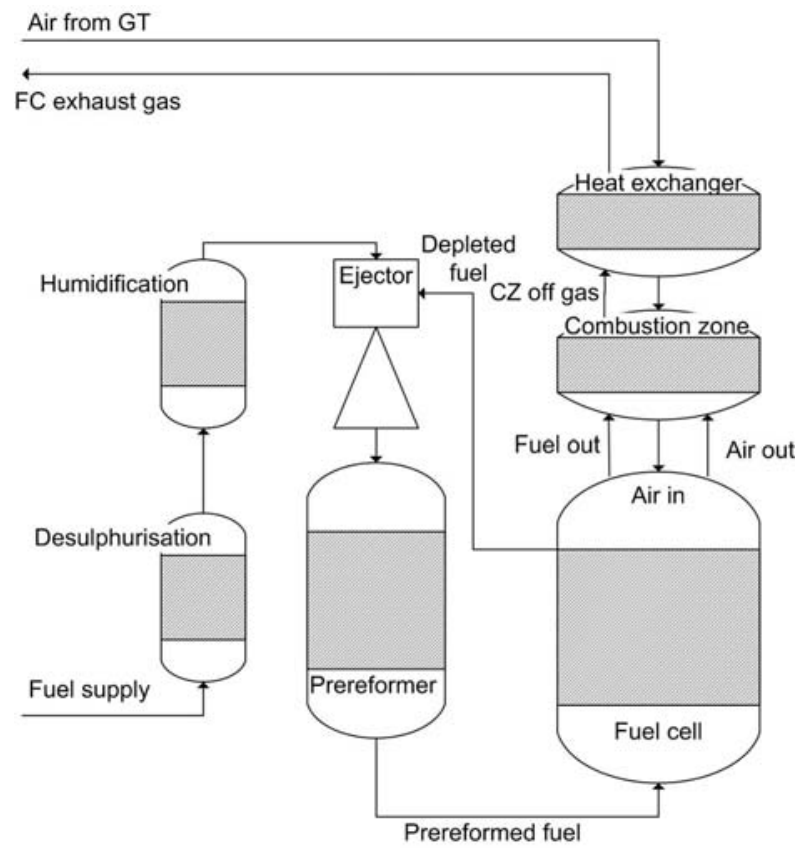

Figure 9. Schematic of the modeled fuel cell system (24). 
The largest scale covered in the present study is the system scale. Here, coupling of the SOFC stack with balance-of-plant components is investigated. The investigations are being carried out in the context of SOFC/gas turbine hybrid power plants, where we model pressurized SOFC subsystems $(22,23)$. The fuel cell system is illustrated in Figure 9. We represent the SOFC stack as single repeat element using a two-dimensional model (MEA plus one channel pair) similar to the one illustrated in Figure 6. The model is used to assess the dynamic operation behavior of the system.

\section{Conclusions}

The SOFC is an outstanding example for a multi-scale and multi-physics system, where processes (both chemistry and transport) and structure take place on all scales from the atomistic level up to the system level. We develop and use mathematical models that couple the various scales in order to achieve a comprehensive understanding of SOFCs. Results were presented from detailed studies on different scales: $(i)$ Patterned anodes are modeled using elementary kinetic reaction-diffusion models which allow a quantitative comparison of electrochemical reaction pathways, including surface spillover and bulk charge transfer reactions; (ii) porous electrode models are developed that include the formation of secondary degradation phases such as $\mathrm{NiO}$ at the anode; (iii) segmented cells are modeled and validated, allowing a detailed insight into the spatial distribution of electrochemical performance and chemical composition of the anode and cathode gases within the electrodes; (iv) The effect of pressurization on electrochemistry and transport in a stack repeat element is investigated based on the models validated on the lower scales; $(v)$ the SOFC subsystem in an SOFC/gas turbine hybrid power plant is modeled, including compressor, reformer, gas recirculation and off-gas combustion, allowing to optimize power output and system efficiency. The activities demonstrate the viability of a multi-scale and multi-physics modeling approach for both, understanding fundamental processes and supporting application design of SOFCs.

\section{Acknowledgments}

This work summarizes contributions of the present and past fuel cell modeling team at the German Aerospace Center (DLR), Institute of Technical Thermodynamics, Stuttgart: Romain Coulon, Max Eschenbach, Moritz Henke, Florian Leucht, Jonathan Neidhardt, Marcel Vogler, Caroline Willich, Vitaliy Yurkiv. Discussions and support from Andreas Friedrich (DLR Stuttgart), Josef Kallo (DLR Stuttgart), Günter Schiller (DLR Stuttgart), Ellen Ivers-Tiffée and group (IWE, Karlsruhe Institute of Technology), Hans-Robert Volpp and group (PCI, Universität Heidelberg), Robert R. Kee (Colorado School of Mines), Alejandro Franco (CEA Grenoble) and Timo Jacob (Universität Ulm) are gratefully acknowledged.

\section{References}

1. W. G. Bessler, S. Gewies and M. Vogler, Electrochim. Acta, 53, 1782 (2007).

2. D. G. Goodwin, Cantera, http://code.google.com/p/cantera (2001-2010).

3. P. Deuflhard, E. Hairer and J. Zugck, Num. Math., 51, 501 (1987). 
4. R. Ehrig, U. Nowak, L. Oeverdieck and P. Deuflhard, in High performance scientific and engineering computing. Lecture notes in computational science and engineering, H.-J. Bungartz, F. Durst and C. Zenger Editors, p. 233, Springer (1999).

5. S. B. Adler and W. G. Bessler, in Handbook of Fuel Cells - Fundamentals, Technology and Applications, Vol. 5, W. Vielstich, H. Yokokawa and H. A. Gasteiger Editors, p. 441, John Wiley \& Sons, Chichester, UK (2009).

6. M. Eschenbach, R. Coulon, A. A. Franco, J. Kallo and W. G. Bessler, Solid State Ionics, in press (2010).

7. M. Neuss-Radu and W. Jäger, SIAM J. Math. Anal, 39, 687 (2007).

8. M. Vogler, A. Bieberle-Hütter, L. J. Gauckler, J. Warnatz and W. G. Bessler, J. Electrochem. Soc., 156, B663 (2009).

9. M. Vogler and W. G. Bessler, ECS Transactions, 25, 1957 (2009).

10. W. G. Bessler, M. Vogler, H. Störmer, D. Gerthsen, A. Utz, A. Weber and E. Ivers-Tiffée, Phys. Chem. Chem. Phys., 12, 13888 (2010).

11. V. Yurkiv, D. Starukhin, H.-R. Volpp and W. G. Bessler, J. Electrochem. Soc., 158, B5 (2011).

12. V. Yurkiv, A. Utz, A. Weber, E. Ivers-Tiffée, H.-R. Volpp and W. G. Bessler, ECS Trans., 35 (2011) (These Transactions).

13. A. Weber, A. Utz, J. Joos, E. Ivers-Tiffée, H. Störmer, D. Gerthsen, V. Yurkiv, H.-R. Volpp and W. G. Bessler, ECS Trans., 35 (2011) (These Transactions).

14. S. Gewies and W. G. Bessler, J. Electrochem. Soc., 155, B937 (2008).

15. S. Gewies, W. G. Bessler, V. Sonn and E. Ivers-Tiffée, ECS Transactions, 7, 1573 (2007).

16. C. Willich, S. Gewies, W. G. Bessler and G. Schiller, in 9th European Solid Oxide Fuel Cell Forum, p. 6-88, Lucerne, Switzerland (2010).

17. J. Neidhardt, M. Henke and W. G. Bessler, ECS Trans., 35, (2011) (These Transactions).

18. W. G. Bessler, in 8th European Solid Oxide Fuel Cell Forum, p. B1101, Lucerne, Switzerland (2008).

19. W. G. Bessler, S. Gewies, C. Willich, G. Schiller and K. A. Friedrich, Fuel Cells, 10, 411 (2010).

20. M. Henke, J. Kallo, K. A. Friedrich and W. G. Bessler, Fuel Cells, submitted (2010).

21. S. Seidler, M. Henke, J. Kallo, W. G. Bessler, U. Maier and K. A. Friedrich, J. Power Sources, in press (2010).

22. F. Leucht, W. G. Bessler, J. Kallo, K. A. Friedrich and H. Müller-Steinhagen, J. Power Sources, 196, 1205 (2011).

23. F. Leucht, W. G. Bessler, J. Kallo, K. A. Friedrich, J. Power Sources, submitted (2011).

24. F. Leucht, W. G. Bessler, J. Kallo and K. A. Friedrich, in 9th European Solid Oxide Fuel Cell Forum, p. 3-53, Lucerne, Switzerland (2010). 